\title{
PENINGKATAN KESELAMATAN PELAYARAN MELALUI PENATAAN INFRA STRUKTUR DI PELABUHAN KALI ADEM MUARA ANGKE JAKARTA UTARA
}

\author{
Ir. Tri Yuli Andaru, M.Si \\ Sekolah Tinggi Transportasi \\ Darat Jl. Raya Setu KM. 3,5 \\ Cibuntu Cibitung Bekasi \\ Tlp: (021) 8254640 \\ Fax: (021) 82608995 \\ info.p3m.sttd@gmail.com
}

\author{
Tarli, SE,. MM, MT \\ Sekolah Tinggi \\ Transportasi Darat Jl. Raya \\ Setu KM. 3,5 Cibuntu \\ Cibitung Bekasi \\ Tlp: (021) 8254640 \\ Fax: (021) 82608995
}

\author{
Drs. Hotlan Silaban, M.Si \\ Sekolah Tinggi \\ Transportasi Darat Jl. Raya \\ Setu KM. 3,5 Cibuntu \\ Cibitung Bekasi \\ Tlp: (021) 8254640 \\ Fax: (021) 82608995
}

\author{
Ir. Djoko Septantyo, MM \\ Sekolah Tinggi Transportasi \\ Darat Jl. Raya Setu KM. 3,5 \\ Cibuntu Cibitung Bekasi \\ Tlp: (021) 8254640 \\ Fax: (021) 82608995
}

\author{
Azhar Hermawan, MT \\ Sekolah Tinggi Transportasi \\ Darat Jl. Raya Setu KM. 3,5 \\ Cibuntu Cibitung Bekasi \\ Tlp: (021) 8254640 \\ Fax: (021) 82608995
}

\section{ABSTRACT}

As it is known today Seaport Crossing Kaliadem Muara Angke, North Jakarta, to Cross Kaliadem jakarta to Pulau Seribu is often water-based transports for tourist destination on Pulau Seribu which is always crowded and needed by the community in the tour, especially on friday, saturday, and sunday so it needs adequate services that the tourism in the Pulau Seribu area can be visited more often and can benefit to the local community and the local government of Pulau Seribu to DKI Jakarta.

As we all know that It is required by users in crossings especially in Kaliadem Muara Angke, Jakarta, will cross over to Pulau Seribu is the availability of infrastructure such as in and out access of the harbor, spacious parking of vehicles, spacious parking terminal and supporting facilities were adequate and safe so we need research into improving the facilities either through increased crossings expand to provide good services to users as well as new construction so Jasan Kaliadem port.

\section{ABSTRAKSI}

Seperti diketahui saat ini Pelabuhan Penyeberangan Kaliadem muara angke jakarta utara untuk Lintas Kaliadem jakarta ke pulau seribu sering merupakan angkutan berbasis air untuk tujuan wisata di pulau seribu yang selalu ramai dan diperlukan oleh masyarakat dalam berwisata khususnya pada hari jumat - sabtu dan minggu sehingga perlu pelayanan yang memdai agar pariwisata di daerah pulau seribu dapat lebih sering dikunjungi dan dapat dirasakan manfaatnya oleh masyarakat setempat serta pemerintah kabupaten pulau seribu pada daerah khusus ibukuta jakarta raya.

Seperti kita ketahui bersama bahwa yang sangat diperlukan oleh nasyrakat pengguna penyeberangan khususnya di kaliadem muara angke jakarta utara yang akan menyeberang ke pulau seribu adalah ketersediaan infrastruktur seperti akses keluar masuk pelabuhan ,luas parkir kendaraan ,luas parkir terminal dan fasilitas penunjang yang memadai dan aman serta berkeselamatan sehingga perlu dilakukan penelitian dalam rangka memperbaiki fasilitas fasilitras tersebut baik melalui peningkatan perluas penyeberangan memberikan pelayanan yang baik kepada pengguna jasan maupun pembangunan baru sehingga pelabuhan Kaliadem. 


\section{PENDAHULUAN}

\section{A. LATAR BELAKANG}

Sektor Transportasi memiliki peran yang sangat penting dalam jaringan pelayanan mobilitas orang dan barang serta kendaraan, sehingga dapat berperan dalam mendukung, mendorong, dan menunjang segala aspek kehidupan, baik dalam bidang ekonomi, politi, sosial, dan budaya, serta pertahanan dan keamanan di masa sekarang maupun masa yang akan datang.

Sehubungan dengan hal tersebut, maka penyelenggaraan angkutan penyeberangan harus terus menerus menunjukkan perbaikan terhadap seluruh fasilitas operasi pelayanan angkutan penyeberangan sehingga memberikan hasil yang optimal dan dapat dirasakan oleh pengguna jasa.

\section{B. IDENTIFIKASI MASALAH}

Dari latar belakang tersebut diatas, maka diperoleh identifikasi masalah sebagai berikut: Dalam rangka menunjang dan meningkatkan pelayanan kepada masyarakat pengguna jasa penyberangan untuk lintas Kali Adem Muara Angke menuju pulau seribu masih terdapat beberapa permasalahan sebagai berikut :

1. Kapal yang beroperasi pada lintas ini adalah kapal penyeberangan dengan type kapal $\mathrm{LO}=\mathrm{LO}$ dan diatur berdasarkan pengelompokan kapal terkait dengan ukuran dan kecepatan kapal.

2. Kondisi prasarana pelabuhan pada sisi darat terutama untuk fasilitas jalan masuk dan keluar pelabuhan,jalan lingkungan ,lapangan parkir serta terminal yang masih belum memadai

3. Kondisi prasarana pelabuhan pada sisi air seperti dermaga masih berbentuk L yang menyebabkan fasilitas sandar yang kurang optimal serta pelayanan navigasi dilaut yang masih perlu peningkatan khususnya dalam rangka peningkatan keselamatan

\section{BATASAN MASALAH}

Dari identifikasi masalah tersebut dapat diketahui masih begitu banyak masalah yang perlu diatasi, tetapi dalam peenelitian ini hanya dibatasi pada penelitian kinerja yang sangat berpegaruh pada efisiensi serta pelayanan infrastrutur pelabuhan baik sisi air seperti bentuk dermaga dan fasilitas keselamatan pelayaran dan beberapa fasilitas darat.

\section{PERUMUSAN MASALAH}


Dalam penelitian ini dapat diperoleh perumusan masalah sebagai berikut :

1. Bagaimana pengaruh operator kapal terhadap penyediaan pelayanan angkutan penyeberangan di Pelabuhan Kaliadem Muara Angke jakarta Lintas jakarta pulau seribu?

2. Bagaimana pengaruh operator dan pengguna jasa terhadap prasarana pelabuhan penyeberangan Kali Adem Muara Angke Jakarta Utara untuk lintas jakarta ke pulau seribu.

\section{E. TUJUAN PENELITIAN}

Tujuan dilakukannya penelitian ini adalah melakukan evaluasi kinerja pelayanan angkutan Penyeberangan di Pelabuhan Kaliadem Muara Angke Lintas jakarta - pulau seribu. Yang terkait hanya untuk infra struktur sehingga nantinya dapat dipertimbangkan untuk dilakukan perbaikan sehingga kinerja pelabuhan penyeberangan tersebut nantinya dapat memnerikan pelayanan dengan optimal.

\section{METODOLOGI PENELITIAN}

\section{A. RENCANA PENELITIAN}

Penelitian dilakukan diwilayah kerja Pelabuhannpenyeberangan angkutan orang di Kali Adem Muara Angke Jakarta Utara yakni didaerah lingkungan kerja dan di lingkungan kepentingan pelabuhan penyeberangan kaliadem seperti akses masuk dan keluar pelabuhan ,jalan lingkungan pelabuhan terminal lapangan parkir serta fasilitas sisi air yaitu dermaga ,kolam pelabuhan dan alur pelayaran serta fasilitas penunjang navigasi untuk keselamatan pelayaran di kolam dan alur pelayaran. 


\section{B. POLA PIKIR}

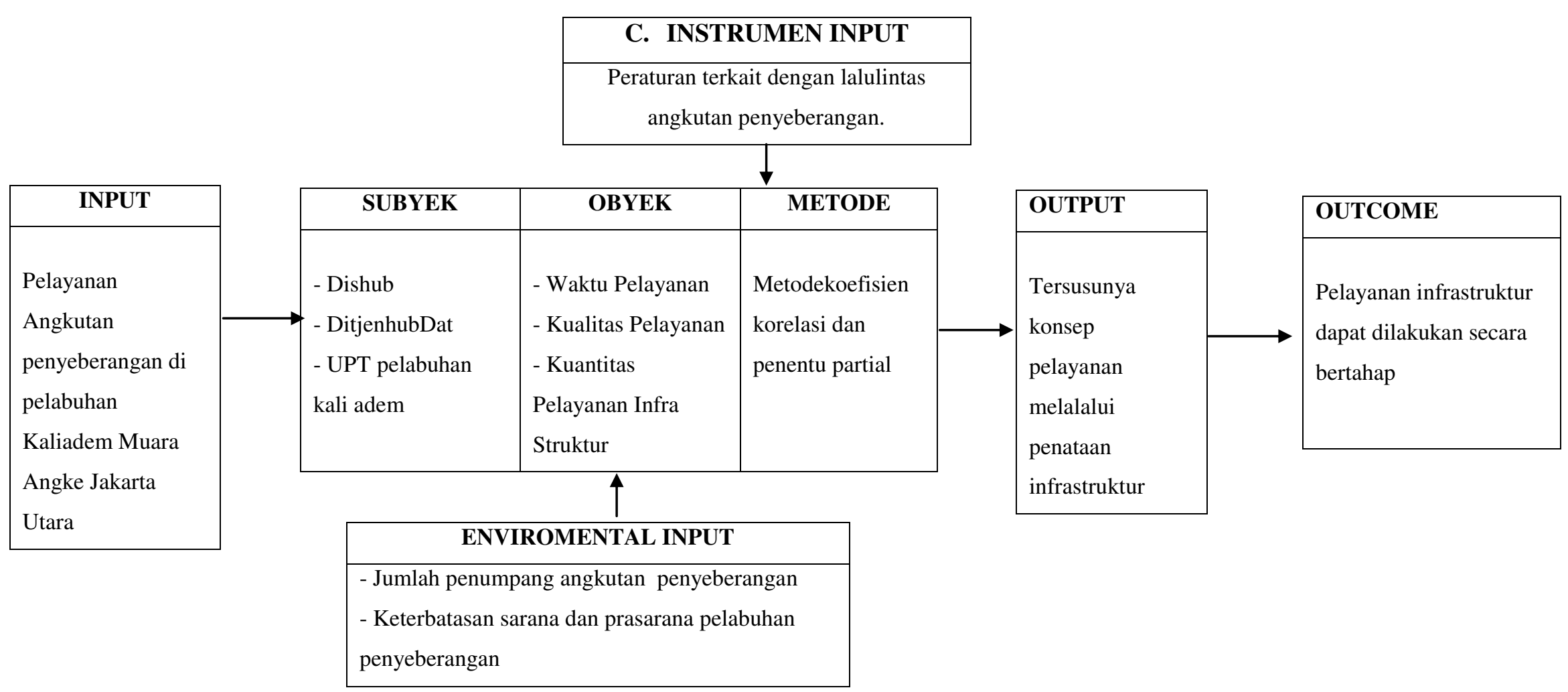




\section{ALUR PIKIR PENELITIAN}

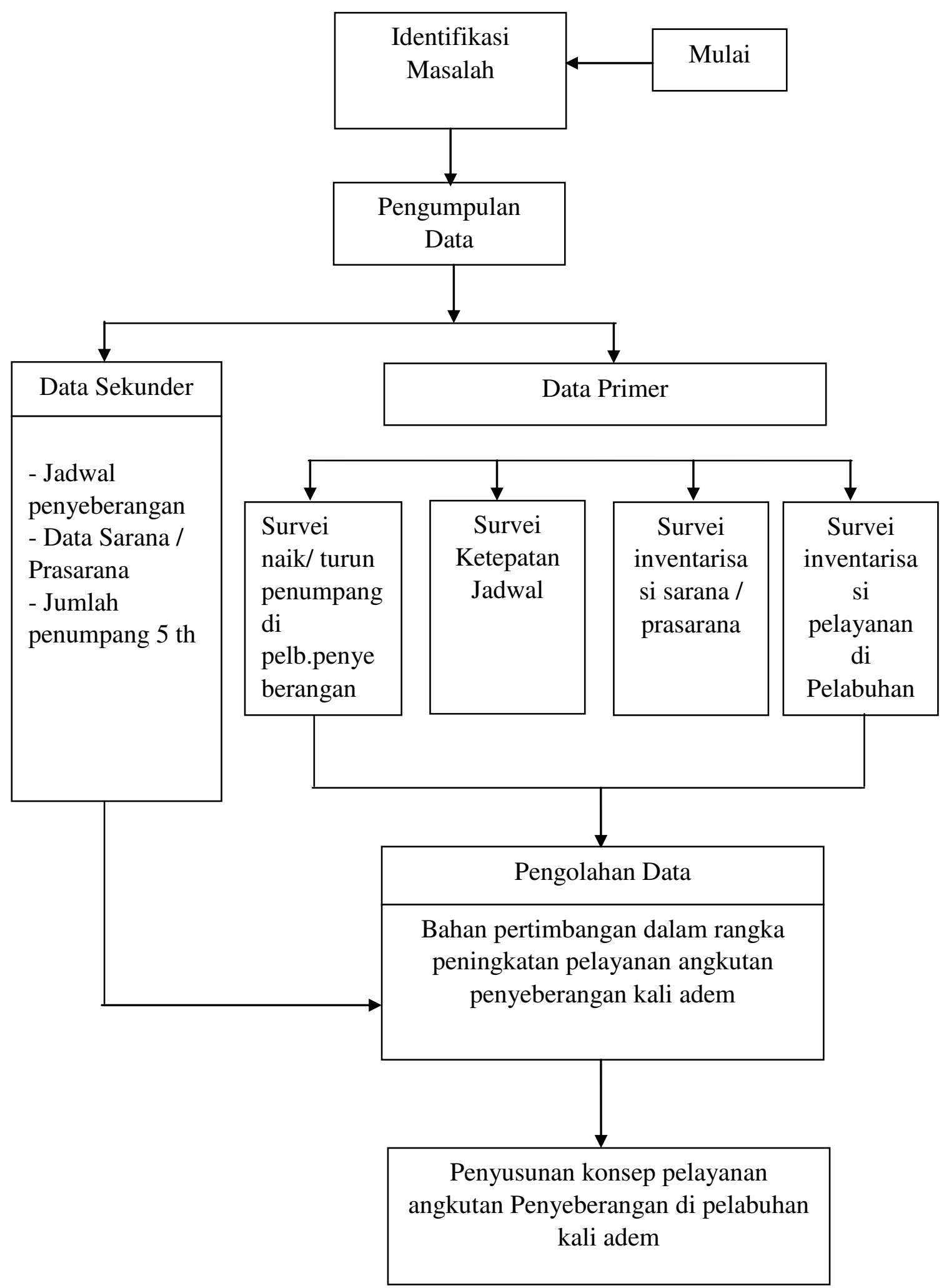




\section{E. METODE PENGUMPULAN DATA}

Metode pengumpulan data yang dilakukan adalah pengumpulan data sekunder yaitu pengumpulan data dari instansi terkait dan kepustakaan serta masukan dari pihak pihak lain seperti konsultan dan pemerhati dibidang transportasi. sedang data primer diambil langsung dilokasi penelitian melalui beberapa survey lapangan yang sesuai dengan kebutuhan.

\section{F. PELAKSANAAN SURVEY}

Survey yang dilaksanakan dalam penelitian ini dalah :

1. Survey inventarisasi fasilitas pelabuhan

2. Survey kinerja pelayanan fasilitas sisi darat

3. Survey kinerja pelayanan fasilitas sisi air

4. Survey kinerja akses keluar masuk pelabuhan

5. Survey tingkt kepuasan pelanggan

6. Survey naik turun penumpang kapal penyeberangan di pelabuhan kaliadem.

\section{G. METODE ANALISA}

Analisa yang digunakan dalam pembahasan penyelesaian penelitian ini adalah :

1. Analisa deskriptif dengan variabel mandiri yang diamati

Seperti tingkat pelayanan melalui :

a. Analisa persyaratan dan perlengkapan fasilitas pelabuhan di pelebuhan penyeberangan Kaliadem Muara Angke Jakarta Utara

b. Analisa pasang surut dan gelombang di pelabuhan penyeberangan Kaliadem Muara Angke Jakarta Utara

c. Analisa kinerja fasilitas sisi darat seperti jalan lingkungan ,lapangan parkir terminal dan fasilitas penunjang lainnya di pelabuhan Kali Adem Muara Angke Jakarta Utara

d. Analisa kinerja fasilitas sisi air seperti dermaga ,kolam pelabuhan dan alur pelayaran serta fasilitas keslamatan dipelabuhan Kali Adem Muara Angke Jakarta Utara

e. Analisa kinerja naik dn turun enumpang kapal penyeberangan di pelabuhan Kali Adem Muara Angke Jakarta Utara.

2. Analisa hubungan melalui koofisien korelasi gamma

( $\mathrm{y}$ ) dengan variabel bebas teramati yaitu tingkat pendidikan dan tingkat kepuasan. 


\section{H. HIPOTESIS}

Pengujian hipotesis dalam penelitian ini digunakan Hipotesis deskriptif dengan menganmati kekuatan variabel mandiri dengan tidak mempersoalkan perbandingan dan hubungan dari variabel melalui rumusan masalah sebagai berikut :

a. Berapakah tingkat pelayanan yang dihasilkan on leh fasilitas sisi darat sisi air pelabuhan Kaliadem Muara Angke di Jakarta Utara tersebut?

Dari rumusan masalah tersebut dituangkan dalam rumusan hipotesis deskriptifnya adalah :

b. Tingkat pelayanan yang dihasilkan oleh kinerja fasilitas sisi darat adalah aa $\%$, kinerja fasilitas sisi air mencapai xx \%, dkinerja naik dan turun penumpang kapal penyeberangan telah jalur mencapai yy \% serta kinerja akses masuk keluar pelabuhan penyeberangan muara angke telah mencapai zz $\%$.

Selain hipotesis deskriptif peneliti juga mencoba menilai kekuatan hubungan antar variabel yang diamati seperti kekuatan hubungan antara tingkat pendidikan dengan tingkat kepuasan konsumen dengan menggunakan analisa hubungan melalui koofisien korelasi gamma ( $\mathrm{y}$ ).

\section{ANALISA DAN PEMBAHASAN}

\section{A. ANALISA DESKRIPTIF}

1. Analisa persyaratan dan perlengkapan fasilitas pelabuhan di pelebuhan penyeberangan Kaliadem Muara Angke

Analisa persyaratan dan perlengkapan fasilitas pelabuhan adalah seluruh persyaratan minimal yang harus diberikan kepada pengguna jasa angkutan penyeberangan serta seluruh kelengkapan fasilitas pokok dan penunjang guna menunjang kelancaran penyelenggaraan angkutan penyeberangan dipelabuhan kaliadem seperti :

a. Terdapat aksesibiliti yang baik guna menunjang transportasi air dipelabuhan kaliadem seperti akses masuk keluar pelabuhan berupa prasarana jalan yang memadai .sedang yang tersedia untuk menunjang pelabuhan kaliadem masih belum memenuhi syarat karena disamping lebar jalan yang kurang memedai yakni hanya $7 \mathrm{~m}$ kondisi jalan juga kurang baik masih terdapat banyak lubang dan bahkan bila musim hujan dan air pasang datang akan terjadi rob dan banjir dan sehingga sangat mengganggu aktifitas dari dan ke pelabuhan penyeberangan kali adem . 
b. Pelayanan akses bagi pengguna jasa yang tidak memiliki kendaraan sendiri telah disediakan angkutan feeder dari trans jakarta ke pelabuhan kaliadem namun jadwal masih tidak beraturan sehingga para penguna jasa menggunakan ojek dengan tarip yang cukup mahal.

c. Pelayanan yang diberikan untuk sandar kapal terlihat sudah cukup baik yakni dengan kedalaman yang sesuai dengan kebutuhan kapal serta labar kolam peli

d. Pelayanan untuk parkir kapal pada saat tidak operasi masih sangat buruk karena masih menjadi satu dengan kapal yang sedang operasi dan terkesn tidak teratur padhal operasi kapal dimulai setiap hari pada pukul 06.30 pagi.

e. Pelayanan naik dan turun penumpang serta barang terlihat masih belum memadai karena mempunyai pola operasi yang masih bersamaan .

f. Pelabuhan kali adem belum mempunyai tempat untuk perbaikan kapal ,sehingga apabila ada kapal yang mengalami gangguan masih merapat didermaga untuk mendapatkan perbaikan.

g. Dari hasil analisis tersebut diatas terlihat bahwa pelabuhan Kali Adem Muara Angke jakara masih perlu peningkatan karena baru memenuhi $87 \%$ persyaratan baik untuk memenuhi persyaratan dan perlengkapan pelabuhan. Sedang secara rinci dapat terlihat pada tabel tersebut dibawah ini :

2. Analisa pasang surut dan gelombang di pelabuhan penyeberangan muara angke analisa pasang surut dan gelombang dipelabuhan penyeberangan Kali Adem Muara Angke dapat dijelaskan sebagai berikut :

a. Selisih pasang surut air laut terendah dan tertinggi adalah antar $90 \mathrm{~cm}$ sampai dengan 1.20 meter dan hal ini seperti biasa yang terjadi dipantai utara pulau jawa .

b. Tinggi gelombang yang biasa terjadi di perairan pantai utara jakarta pada saat sat tertentu yakni antara bulan september sampai dengan desember dan januari adalah dengan tinggi grlombang tertinggi 5 sampai dengan 6 meter dan terendah adalah antara 5mpai dengan 1 meter

c. Sedang type pasang surut yang terjadi terdapat beberapa type yaitu type pasang surut campuran dengan condong ke pasang surut harian tunggal dan akan terjadi pada satu kali air pasang dan satu kali air surut tetapi kadang kadang untuk sementara waktu dapat terjadi dua kali air pasang dan dua kali air surut dengan tinggi dan periode yang sangat berbeda. 
d. Dari hasil analisis pasang surut dan gelombang di pelabuhan kali adem jakarta masih cukup aman namun perlu diwaspadai adanya rob dan pendangkalan terhadap kolam pelabuhan serta alur pelayaran.

3. Analisa kinerja fasilitas sisi darat seperti jalan lingkungan ,lapangan parkir terminal dan fasilitas penunjang lainnya di pelabuhan Kali Adem Muara Angke Jakarta Utara.

Analisa kinerja fasilitas sisi darat pada pelabuhan Kaliadem Muara Angke Jakarta Utara dapat di jelaskan sebagai berikut :

a. Akses jalan keluar masuk dari dan ke pelabuhan kali adem

Akses keluar dan masuk ke pelabuhan kali adem cukup jauh yakni panjang jalan tidaak lebih dari satu km dengan lebar jala lebih kurang tujuh meter dengan kondisi jalan banyak yang berlubang serta banyak penghalang dikiri dan kanan jalan karena masih terkait dengan perumahan nelayan dan pembuangan sampanh dan apabila terjadi hujan dan rob jalan tersebut akan banjir dan akan mengganggu akses kelun masuk pelabuhan penyeberangan kali adem.

b. Jalan lingkungan pelabuhan

Jalan lingkungan didalam pelabuhan kaliadem masih cukup baik bila digunakan dalam keadaan tidak sibuk namun apabila digumakan pada saat hari sibuk akan menjadi kurang memadai karena jalan lingkungan di pelabuhan kali adem berbentuk Huruf Ldengan perkerasan fleksibel pavement dengan permukaan perkerasan cukup baik sedang kinerja jalan lingkungan telah mencapai $72 \%$.

c. Lapangan parkir kendaraan

1;apangan parkir pelabuhan kali adem mempunyai luas sekitar $35000 \mathrm{~m}^{2}$ sehingga dapat digunakan untuk parkir zebanyak lebih kurang 40 kendaraan kecil dan 5 buah bus besar dan kondisi ini masih belum memadai apabila dalam keadaan hari sibuk sehingga untuk lebih jelasnya dapat terlihat pada gambar tersebut dibawah ini perlu dilakukan perluasan parkir agar dapat menampung jumlah kendaraan yang cukup banyak sedang kinerja lapangan parkir tekah mencapai $87 \%$.

d. Ruang tunggu keberangakata

Fasilitas ruang tunggu keberangkatan di plabuhan kali adem sudah cukup baik dengan lebar 3 meter dan panjang lebih kurang 150 meter cukup untuk menampung jumlah orang yang sesua dengan kapasitas kapal yang tersedia 
namun demikian bagi penumpanh yang tidak menggunakan ruang tunggu dapat menunggu di bus maupun kendaraan pribadi masing masing sedang kinerja ruang tunggu telah mencapai $89 \%$ sehingga memang sudah cukup padat .

e. Fasilitas penunjang listrik telepon dn air bersih

Fasilitas penunjang pelabuhan penyeberangan kali adem seperti untuk komunikasi dengan telepon maupun radio SSB Sudah cukup memadai ,selain ituuntuk fasilitas air bersih disuplay selain oleh perusahaan air minum juga oleh sumur artetis sehingga pasokan air bersih untuk kebutuhan didarat dan dikapal masih dapat terlayani dengan baik

f. Fasilitas depo bahan bakar

fasilitas depo bahan bakat melakukan pelayaran sangat diperlukan oleh kapal penyeberangan sehingga dapat melakukan sampai dengan tujuan dan apabila di tempat tujuan tidak terdapat bahan bakar maka perlu mabawa bahan bakar yang telah disediakan dipelabuhan asal dan untuk prlabuhan kaliadem untuk persediaan bahan bakar sudah cukup memadai dan disediakan oleh kapal kapal pengangkut bahan bakar selain itu juga ada operator yang sudah menyiapkan bahan bakar dengan membeli di Stasiun pompa bensin terdekat dengan pelabuhan.

g. Fasilitas pemadam kebakaran

Fasilitas pemadam kebakaran disiapkae pemerintah daerah yang berlokasi didekat pelabuhan sehingga apabila terjadi sesuatu pemadam kebaran siap untuk melakukan pemadaman sedang untuk pemadaman dilaut untuk pelabuhan kali adem masih belum tersedia.

4. Analisa kinerja fasilitas sisi air seperti dermaga ,kolam pelabuhan dan alur pelayaran serta fasilitas keslamatan dipelabuhan kali adem muara

Analisa kinerja fasilitas sisi air pada pelabuhan Kaliadem Muara Angke Jakarta Utara dapat dijelaskan sebagi berikut
a. Fasilitas sandar dermag
b. Fasilitas kolam pelabuhan
c. Fasilitas penahan gelombang
d. Fasilitas peralatan pemandu keselamatan pelayaran

5. Analisa kebutuhan fasilitas pelabuhan melalui penataan infra struktur di pelabuhan kali adem. 
Analisa kebutuhan fasilitas pelabuhan melalui penataan infra struktur dipelabuhan kali adem dapat dijelaskan sebagai berikut :

Pelabuhan kali adem merupakan pelabuhan penyeberangan kelas 111 dengan kriteria :

a) Volume angkutan

1) Jumlah penumpang $<1000$ orang per hari

2) Kendaraan tidak melayani angkutan kendaraan

b) Frekwensi

$<6$ trip per hari

c) Kapal yang beroperasi

$<500$ GRT

d) Waktu operasi

$<8$ Jam Operasi

e) Fasilitas pokok minimal yang harus disediakan

f) Fasilitas perairan yang harus disediakan

g) Fasilitas daratt yang harus disediakan

6. Analisa ketersediaan fasilitas penyeberangan di pelabuhan kali adem Jakarta Utara Analisis ketersediaan fasilitas lintasan penyeberangan ,kapal dan sistem operasi di pelabuhan kali adem Jakarta Utara dapat dijelaskan sebagai berikut :

a. Lintasan penyeberangan

Angkutan penyeberangan lintas kalia adem Jakarta Utara menuju pulau pulau yang tersebar di pulau seribu seperti pulau tidung dan pulau harapan serta pulau pulau lainya mempunyai panjang lintasan n kurang lebih 150 mil dan merupakan lintas penyeberangan komersil yang dikelola oleh dinas perhubungan propinsi DKI Jakarta guna menunjang sektor pariwisata di daerah jakarta kh inihususnya di Pulau Seribu.

b. Jenis kapal yang melayani

Kapal yang melayani angkutan penyeberangan lintas kali adem pulau seribu adalah kapal jenis LO - LO dengan bobot antara 100 sampai dengan 150 GRT dengan jumlah penumpang maksimal 150 orang dan tidak memuat kendaraan.

c. Pola operai pelayanan penyeberangan

Pola operasi pelayanan penyeberangan adalah para penumpang yang akan melakukan dan membutuhkan pelayanan penyeberangan ke pulau seribu dapat langsung membeli tiket di agen agen pelayanan penyeberangan atau travel biro pariwisata serta dapat langsung membeli tiket di pelabuhan kaliadm selama persediaan masih ada.

7. Analisa kinerja naik dan turun Penumpang kapal penyeberangan di pelabuhan Kali Adem Muara Angke. 
Analisa kinerja naik dan turun penumpang kapal penyeberangan dikali adem untuk hari hari biasa untuk setiap kapal dengan pemberangkatan pertama jam 06.30 pagi hanya sekiitar 50 sampai dengan $60 \%$ sedng kinerja penumpang tertinggi adlah pada hari sabtu dan minggu yakni sekitar hampir $100 \%$ dan bahkan ada yang melebihi kapasitas angkut smpai dengan $125 \%$ dan hal ini sangat berbahaya dan memerlukan pengawasan yang lebih ketat oleh aparat perhubungan setempat.

\section{KASIMPULAN DAN SARAN}

\section{A. KESIMPULAN}

Dari hasil pembahasan mengenai kondisi infra struktur pelabuhan Kali Adem Muara Angke yang terletak di pantai ura jakarta tersebut dapat ditarik kesimpulan sebagai nerikut :

1. Persyaratan dan perlengkapan fasilitas pelabuhan di pelebuhan penyeberangan Kaliadem Muara Angke Jakarta Utara sudah terdapat aksesibiliti yang baik guna menunjang transportasi air di pelabuhan kaliadem seperti akses masuk keluar pelabuhan berupa prasarana jalan yang memadai .sedang yang tersedia untuk menunjang pelabuhan kaliadem masih belum memenuhi syarat karena disamping lebar jalan yang kurang memedai yakni hanya $7 \mathrm{~m}$ kondisi jalan juga kurang baik masih terdapat banyak lubang dan bahkan bila musim hujan dan air pasang datang akan terjadi rob dan banjir dan sehingga sangat mengganggu aktifitas dari dan ke pelabuhan penyeberangan kali adem, sedang pelayanan akses bagi pengguna jasa yang tidak memiliki kendaraan sendiri telah disediakan angkutan feeder dari trans jakarta ke pelabuhan kaliadem namun jadwal masih tidak beraturan sehingga para penguna jasa menggunakan ojek dengan tarip yang cukup mahal. Untuk Pelayanan yang diberikan untuk sandar kapal terlihat sudah cukup baik yakni dengan kedalaman yang sesuai dengan kebutuhan kapal serta labar kolam pelabuhan. Pelayanan untuk parkir kapal pada saat tidak operasi masih sangat buruk karena masih menjadi satu dengan kapal yang sedang operasi dan terkesn tidak teratur padhal operasi kapal dimulai setiap hari pada pukul 06.30 pagi Pelayanan naik dan turun penumpang serta barang terlihat masih belum memadai karena mempunyai pola operasi yang masih bersamaan sementara itu. Pelabuhan kali adem belum mempunyai tempat untuk perbaikan kapal ,sehingga apabila ada kapal yang mengalami gangguan masih merapat didermaga untuk mendapatkan perbaikan .Sehingga Dari hasil analisis tersebut diatas terlihat bahwa pelabuhan Kali Adem Muara Angke jakara masih perlu 
peningkatan karena sudah mencapai $87 \%$ dari keseluruhan perlengkapan pelabuhan tersebut.

2. Pasang surut dan gelombang di pelabuhan penyeberangan Kaliadem Muara Angke jakarta utaar yakni terjadi Selisih pasang surut air laut terendah dan tertinggi adalah antar $90 \mathrm{~cm}$ sampai dengan 1.20 meter dan hal ini seperti biasa yang terjadi dipantai utara pulau jawa .sedang Tinggi gelombang yang biasa terjadi di perairan pantai utara jakarta pada saat sat tertentu yakni antara bulan september sampai dengan desember dan januari adalah dengan tinggi grlombang tertinggi 5 sampai dengan 6 meter dan terendah adalah antara 5mpai dengan 1 meter . type pasang surut yang terjadi terdapat beberapa type yaitu type pasang surut campuran dengan condong ke pasang surut harian tunggal dan akan terjadi pada satu kali air pasang dan satu kali air surut tetapi kadang kadang untuk sementara waktu dapat terjadi dua kali air pasang dan dua kali air surut dengan tinggi dan periode yang sangat berbeda. Dari hasil analisis pasang surut dan gelombang di pelabuhan kali adem jakarta masih cukup aman namun perlu diwaspadai adanya rob dan pendangkalan terhadap kolam pelabuhan serta alur pelayaran.

3. Fasilitas sisi darat seperti jalan lingkungan ,lapangan parkir terminal dan fasilitas penunjang lainnya di pelabuhan Kali Adem Muara Angke Jakarta Utara serta kinerja fasilitas sisi air seperti dermaga ,kolam pelabuhan dan alur pelayaran serta fasilitas keslamatan dipelabuhan Kali Adem Muara Angke Jakarta Utara sudah mencapai antar $76 \%$ samoai dengan $90 \%$.

4. Kebutuhan fasilitas pelabuhan melalui penataan infra struktur untuk 25 tahun mendatang sudah harus perlu dioikirkan seperti daerah lingkungan kerja dan kepentingan pelabuhan untuk memperluas dan memperpanjang dermaga kolam pelabuhan ,lapangan parkir dan ruang tunggu penumpan.

\section{B. SARAN}

Dari kesimpulan diatas maka disarankan untuk dilakukan penelitian lanjutan yang lebih mendalam dan sangat detail guna meningkatkan ketersediaan fasilitas infra struktur di pelabuhan kali adem jakarta melalui masterpalan sampai dengan kebutuhan 25 tahun mendatang,sehingga akan diketahui berapa kebutuhan fasilitas pokok dan pendukung sehingga pelayanan penyeberangan khususnya untuk menunjang pariwisata dapat terlaksana dengan baik dan memuaskan . 